\title{
Donde habita el olvido: Conformación y desarrollo del espacio público en el primer cuadro de la ciudad de Monterrey, 1980-2007
}

Reynaldo de los Reyes Patiño

(iD) http://orcid.org/oooo-0003-1691-2410

El Colegio de México, México

reynaldo.reyesp@gmail.com

Jaime Sánchez-Macedo, Donde habita el olvido: Conformación y desarrollo del espacio público en el primer cuadro de la ciudad de Monterrey, 1980-2007, Monterrey, CONARTE, 2019, 263 pp. ISBN: 978-607-8598-23-6

Dicen que no hay mejor memoria que la de los elefantes, pero, según tengo entendido, esta condición no se presenta en algunos ejemplares como los elefantes blancos. Raros especímenes que aparecen al menos una vez cada seis años, pero prefieren olvidar sus traumáticas historias manchadas de intereses políticos. Afortunadamente, ahora contamos con historiadores que se preocupan por seguir las huellas de esos mamíferos y rescatar su memoria, que tantas cosas nos revela sobre los humanos. Un caso notable en esto es el libro de Jaime Sánchez-Macedo, Donde habita el olvido: Conformación y desarrollo del espacio público en el primer cuadro de la ciudad de Monterrey, 1980-2007, que desentraña la construcción de tres monumentales obras públicas construidas en la capital nuevoleonesa durante ese periodo: la Gran Plaza (Macroplaza), el Parque Fundidora y el Paseo Santa Lucía, para mostrar cómo su articulación facilitó "la mercantilización del espacio urbano” y generó “procesos de expulsión de población que hoy en día contribuyen a perpetuar la imagen ruinosa y de abandono dentro del primer cuadro de la ciudad" (p. 35).

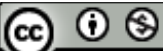

4.0 Internacional

Secuencia. Reseñas, 2021

http://secuencia.mora.edu.mx
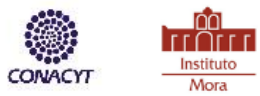
Para Sánchez-Macedo, "la obsesión de crear una nueva imagen urbana siempre a costa del pasado" (p. 44), llevó a que las autoridades estatales emprendieran proyectos de modernización autoritarios (la creación de espacios públicos "planificados") que arrasaron con gran parte del patrimonio físico y social del centro de Monterrey (espacios públicos “contingentes”). Y, sin embargo, como se muestra a lo largo de la obra, el olvido que buscaron unos se volvió la nostalgia de otros, de los desplazados, o de los "ex habitantes", como el autor propone llamarlos, quienes pasaron a reclamar sus espacios por medio de la memoria. A mi juicio, es en este punto donde reside el principal aporte del libro. La mirada de Sánchez-Macedo no es del que piensa en lugares absolutos, sino en espacios disputados, donde lo contingente choca con el control y la imagen que el Estado y el capital buscan imponer.

Para desarrollar este enfoque, el autor presenta en el prefacio algunas nociones teóricas (H. Lefebvre, M. de Certeau, D. Harvey, A. Giglia) que le sirven para articular el trabajo a lo largo de tres capítulos: uno que habla de la creación del espacio público planificado; otro de las formas de espacio público contingente; y un último centrado en la idea del patrimonio. Sánchez-Macedo recurre a una buena diversidad de fuentes que incluyen archivos estatales y municipales, fotografías, videos, hemerografía, cartografía, literatura y una serie de entrevistas semiestructuradas. El libro es un buen ejemplo de cómo revisitar fuentes que ya habían sido utilizadas y también de cómo rescatar voces en registros que habían pasado desapercibidos (una muestra, la reconstrucción del espacio ocupado por la Gran Plaza a través del análisis de fotografías). Como siempre, la tensión entre el aparato conceptual y los objetos y sujetos de estudio se hace presente y deja algunos cuestionamientos: ¿La Gran Plaza, por ejemplo, puede asumirse como un proyecto neoliberal, o más bien es parte de un estatismo trasnochado? ¿Cómo es que la Fundidora (y no otras fábricas) llegó a constituir un "espacio público contingente"? El autor da algunas pistas, pero un poco más de análisis no habría venido mal.

El valioso aporte que representa una mirada a nivel de calle también puede tener algunos inconvenientes. Uno de ellos es que, al estar tan centrado en esa mirada horizontal, es fácil perder de vista la escala y el contexto de las 
transformaciones urbanas, puntos clave si tomamos en cuenta el acelerado proceso de urbanización de América Latina en la segunda mitad del siglo XX. Algunas dudas surgen a consecuencia de ello: el crecimiento de la población y de la zona urbana; el perfil social y económico de la ciudad; e incluso la evolución del poder político, que no parece cambiar a lo largo del texto. Por último, también se extrañan las comparaciones, pues, como el autor reconoce al final del libro, hay cosas como "la influencia de modelos de gestión urbana provenientes del extranjero" que resultan "un tema pendiente a desarrollar en investigaciones posteriores" (p. 238).

Parece que, al menos en el caso de la Gran Plaza (una obra que implicó la transformación de más de 30 manzanas del centro de la ciudad) la dificultad en la comparación residió en encontrar otra obra que fuera al mismo tiempo tan grande y fea. Sánchez-Macedo cita una crítica de Monsiváis a este proyecto, donde señala que su construcción es parte de la fiebre monumental y del discurso triunfalista del presidente José López Portillo en medio del auge petrolero, y aunque intervenciones similares se dieron en Guadalajara y Tuxtla Gutiérrez, las dimensiones fueron mucho menores. Agrega Monsiváis:

Si la queja habitual a propósito de Monterrey es su fealdad orgánica, su carácter de objetivación arquitectónica y habitacional de un capitalismo negado entre otras cosas a los estímulos visuales, tan concentrado en la acumulación que no se dio tiempo para el mínimo capricho estético, la Macroplaza es la continuación lógica (y la celebración) de tal espíritu (p. 192).

Pero como bien saben los regiomontanos, todo es más grande y casi también más feo en el vecino estado de Texas, por lo que quiero traer a colación algo así como un antecedente de la Gran Plaza en esa entidad y ofrecer una lectura desde el punto de vista de los estudios de la infraestructura. No sé si hubo relación entre estos proyectos, pero justifico la mención por la similitud en la escala y por su cercanía con Monterrey, ya que tuvo lugar en la ciudad de Houston, donde el auge petrolero también estaba haciendo de las suyas e incentivó un afán de transformación urbana fuera de proporción. Ahí no fueron las autoridades estatales, sino una compañía privada de transporte de gas la que hacia 1970 intentó crear la "ciudad del futuro" y adquirió 32 manzanas del downtown para desarrollar un complejo de edificios llamado Houston Center. Según el diseño del arquitecto futurista William Pereira, el 
complejo incluiría cuatro pisos de estacionamientos subterráneos, diversos medios de transporte interno, largos tramos de plazas y jardines elevados, y múltiples rascacielos con espacios residenciales, comerciales y de entretenimiento. Pereira intentó hacer de Houston 'un precedente y un prototipo para las ciudades del tercer milenio', pero por motivos que no mencionaré aquí, el proyecto fracasó (Castaneda \& Pratt, 1993, pp. 173-187). La visión transformadora, sin embargo, estaba ya en otros proyectos, y como indica un historiador, consistió en renovar el "decadente" centro de Houston, removiendo los tradicionales barrios de afroamericanos y sustituyéndolos por "ambientes públicos controlados", con nuevos edificios de oficinas y centros comerciales que, conectados por túneles y pasadizos elevados (skyways), permitirían a algunos moverse de manera "segura" y en la comodidad del aire acondicionado (Thompson, 2007, p. 99).

A los diseñadores de la Gran Plaza, en Monterrey, se les olvidó contemplar el aire acondicionado, e incluso colocar ventilación en los espacios subterráneos (lo menciona Sánchez-Macedo, p. 81); sin embargo, me parece que la lógica de los dos proyectos era similar: borrar del mapa lo indeseado, que sí podía ser el calor, pero sobre todo los otros, "esos otros que no son los que deberían estar allí: los migrantes, los homosexuales, los obreros y los pobres" (p. 245), que perdieron sus espacios para abrirle paso al progreso. Parecería entonces que ese tipo de proyectos no buscó resolver problemas de vivienda, de precariedad laboral o de higiene, como señalaban sus promotores, sino simplemente desplazar esos problemas a las periferias, de manera que pudiera crearse una "burbuja primermundista" (p. 241) para tratar de ocultar lo que para el Estado y el capital resultaba ominoso.

Como sugieren Appel, Anand \& Gupta en The Promise of infrastructure (2018), estudiar la vida material y política de las infraestructuras "socava los discursos de progreso tecnológico, igualdad liberal y crecimiento económico, revelando las frágiles y violentas relaciones entre las personas, cosas e instituciones que las controlan o proveen” (p. 3). Esto queda claro en el libro de Sánchez-Macedo, quien muestra además cómo lo que se disputa no son sólo recursos o espacios tangibles, sino también "el derecho a la memoria en la ciudad", que no es otra cosa que "el derecho a reconocerse en el espacio urbano, a no ser desahuciado, a tener voz 
y voto sobre el desarrollo y porvenir de nuestro entorno cotidiano", y a "no sucumbir ante el olvido" (p. 246).

El planteamiento del libro me recordó las palabras del urbanista de una novela que, en el Berlín reunificado, se lamentaba también del carácter destructivo del urbanismo del siglo XX. Para cerrar, reproduzco aquí un fragmento de esa carta:

Quisiera hablar del olvido a escala humana y social, explicar por qué nos es indispensable y cómo el urbanismo ha sido aliado del olvido; un olvido montado en grúas y maquinaria pesada y que acaba por morderse la cola: cuando cree que ya ha terminado con la ciudad antigua, vieja, insalubre, ineficiente, inmencionable, ya no es olvido sino memoria sobre la que otros quieren reconstruir, la que otros quieren olvidar (Tenorio-Trillo, 2004, p. 18).

Sin lugar a duda, Donde habita el olvido es un libro que contribuye a la reconstrucción de esas memorias que otros han querido borrar. Al final, la lección parece simple: la serpiente quiso engullir al elefante, y terminó mordiéndose la cola.

\section{Referencias}

Appel, H., Anand, N., \& Gupta, A. (2018). Introduction. Temporality, Politics, and the Promise of Infrastructure. En N. Anand, H. Appel, \& A. Gupta (Eds.), The Promise of Infrastructure (pp. 1-38). Durham: Duke University Press.

Castaneda, C. J., \& Pratt, J. A. (1993). From Texas to the East: a strategic history of Eastern Corporation. College Station: Texas A\&M University Press.

Tenorio-Trillo, M. (2004). El urbanista. México: Fondo de Cultura Económica.

Thompson, R. S. (2007). “The Air-Conditioning Capital of the World": Houston and Climate Control. En Energy metropolis: an environmental history of Houston and the Gulf Coast (pp. 88-107). Pittsburgh: University of Pittsburgh Press. 